\title{
Envelhecimento em contexto de superexploração e contrarreformas*
}

\author{
Aging in the context of over \\ exploitation and contrarreforms
}

\author{
Solange Maria Teixeira ${ }^{a}$ \\ (D) http://orcid.org/0000-0002-8570-5311
}

\begin{abstract}
Resumo: 0 objetivo deste artigo é apresentar uma análise do envelhecimento humano, na perspectiva da gerontologia crítica, reconstruindo as homogeneidades nas experiências de envelhecimento e velhice em novas bases - histórica e ontológica - por meio de um quadro atualizado dos determinantes sociais, sem os quais as análises dos modos de envelhecer seriam meras abstrações. É um estudo decorrente de pesquisa teórica, com metodologia qualitativa e de escolha intencional das referências bibliográficas. Conclui que as mudanças em curso decorrem da ofensiva da classe dominante contra a classe trabalhadora, que generaliza a superexploração, o contingente de sobrantes e a pobreza, ameaçando o futuro das atuais gerações e o seu envelhecimento com dignidade.
\end{abstract}

Palavras-chave: Envelhecimento. Superexploração. Superpopulação Relativa. Políticas Sociais.

\begin{abstract}
The objective of this article is to present an analysis of human aging, from the perspective of critical gerontology, reconstructing the homogeneities in the experiences of aging and old age on new bases, both historical and ontological. Presenting an updated picture of social determinants without which the analysis of ways of aging would be mere abstractions. It is an article resulting from theoretical research, with qualitative methodology and intentional choice of bibliographic references. It is concluded that the changes in course, result from the offensive of the dominant class against the working class, which generalizes over-exploitation, the contingent of people left over and poverty threatening the future of the current generations, and their aging with dignity.
\end{abstract}

Keywords: Aging. Overexploitation. Relative Overpopulation. Social Politics.

*O artigo é resultante da pesquisa "Envelhecimento e proteção social da assistência social” financiada pelo CNPq na modalidade de bolsa de produtividade e pelo edital Universal de 2018, na faixa C.

aUniversidade Federal do Piaú (UFPI), Teresina/PI, Brasil.

Recebido: 12/4/21 - Aprovado: 15/6/21 


\section{Introdução}

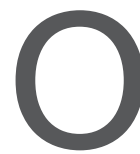

campo científico é marcado por disputas de hegemonia de saberes e práticas. Na ciência do envelhecimento humano, apesar de ser uma área nova, a sua dimensão multidisciplinar torna-o mais complexo e disputado, dificultando consensos conceituais.

Como destaca Debert (1992, p. 33-34), “[...] a hipótese que funda a gerontologia como campo específico de estudos é a de que a velhice homogeneizaria as experiências vividas ou que os problemas enfrentados pelos idosos são tão prementes e semelhantes que minimizariam as diferenças [...]", tais como as diferenças de classe, gênero, raça ou etnicidade e outras.

Essa tendência homogeneizante perdura até os dias atuais, seja na compreensão do envelhecimento como declínio, decadência, improdutividade, pobreza, abandono, como problema social; seja dos idosos como seres ativos, participativos, independentes, autônomos que ressignificam suas experiências e representações da velhice, projetam-se para o futuro com disposição e saúde, o que deu origem às expressões "terceira idade", "melhor idade", dentre outras.

Debert (1992) aponta, com base em uma revisão sistemática de literatura, que os estudos sociológicos e antropológicos criticavam essa homogeneidade, e destacavam as diferenças de classe e etnicidade como elementos que diferenciavam as experiências de envelhecimento, além de apontar também os impasses, as dificuldades e os limites dessas pesquisas.

As críticas atingiam tanto a dimensão cronológica quanto as biomédicas, que tomavam o envelhecimento e a velhice como ciclos de vida, partes de um processo "natural" - pensados como sequências abstratas e predeterminadas, independentemente das condições socioeconômicas e culturais -, ou quando os consideravam como influenciadores do processo, apenas como meros contextos externos ou panos de fundo dos acontecimentos biológicos.

Atualmente, há unanimidade na gerontologia em reconhecer o envelhecimento como um processo biopsicossocial, complexo, multidimensional 
e heterogêneo. Entretanto, muitas análises que criticam os demarcadores cronológicos homogeneizadores e generalizantes para defender a heterogeneidade nas formas de envelhecer caem no outro extremo, a singularização ou subjetivação das formas de envelhecer e viver a velhice, ou seja, chegam a "[...] uma pluralidade de experiências individuais que impossibilita retê-la em um único conceito ou noção ao investigá-la [...]" (Siqueira; Botelho; Coelho, 2002, p. 905).

O objetivo deste artigo é problematizar tanto as perspectivas de análise do envelhecimento homogeneizantes, a-históricas e abstratas, quanto as que o analisam como um processo heterogêneo, com base em diferentes idades complementares ou dissonantes e na singularização das experiências de velhice, além de propor uma perspectiva de análise crítica que situa os indivíduos em suas condições de existência e historicidade, apresentando um quadro de agravamentos dessas condições que afetará as diferentes gerações, tanto os que hoje são jovens, quanto os que já são velhos, diante da generalização da superexploração, da superpopulação relativa e dos desmontes dos sistemas de proteção social.

\section{Envelhecimento humano e a diversidade das condições de existência}

Tornaram-se comuns as perspectivas de análises que defendem a diversidade e a heterogeneidade no modo de envelhecer e viver a velhice. Algumas perspectivas analisam o envelhecimento como um caleidoscópio de idades - a biológica, a psicológica, a social e a cronológica.

A idade biológica é definida pelas modificações orgânicas, fisiológicas, corporais e mentais que ocorrem ao longo do processo de desenvolvimento humano, da concepção à morte.

[...] o envelhecimento é interpretado em ligação com teorias que explicam as causas do envelhecimento celular e $o$ aparecimento de perturbações de saúde que, por sua vez, contribuem para a diminuição das possibilidades 
de sobrevivência à medida que a idade avança (Silva, 2006; Vaz, 2008 apud Carvalho, 2013, p. 4).

A idade psicológica se relaciona às capacidades psicológicas, cognitivas e comportamentais, tais como: percepção, aprendizado, memória e senso subjetivo de idade, e é medida por elas. Segundo Schneider e Irigary (2008, p. 591), “[...] em parte, a caracterização do indivíduo como velho é dada quando ele começa a ter lapsos de memória, dificuldade de aprendizado e falha na atenção, orientação e concentração, comparativamente com suas capacidades cognitivas anteriores".

A idade social está ligada ao conjunto de hábitos, papéis sociais, normas que os indivíduos adotam, conscientemente ou não, ou que são forçados a adotar pela força dos costumes de um determinado tempo histórico, postos pelas regras sociais do meio em que vivem, sendo diferenciados e esperados de acordo com a idade (Schneider; Irigary, 2008; Carvalho, 2013).

A idade cronológica, que mensura a passagem do tempo em dias, meses e anos, desde o nascimento, é, de acordo com Schneider e Irigary (2008), a mais usual e simples forma de obter informações de uma pessoa, porém, não é um determinante do processo de desenvolvimento, sendo apenas um demarcador socialmente criado a partir das idades para fazer a separação entre os segmentos (infância, adolescência, adulto, velhice), criações da vida moderna e das políticas públicas.

Essas idades (biológica, psicológica, social e cronológica) podem variar muito de pessoa para pessoa, e em uma mesma pessoa elas podem ser complementares ou dissonantes entre si. Como ressaltam Schneider e Irigary (2008, p. 592), “[...] a variabilidade de cada pessoa (genética e ambiental) acaba impedindo o estabelecimento de parâmetros [...]", extremando a singularização do processo do envelhecimento.

Além disso, esse tipo de análise é meramente descritivo, como se as idades ou cada elemento que compõem o processo biopsicossocial ocorressem independentemente do outro e pudessem ser isolados da totalidade 
em que se processam, tanto do ser humano (como ser social) quanto da sociedade em que envelhece. Como ressalta Beauvoir (1970, p. 26):

A gerontologia desenvolveu-se em três planos: o biológico, o psicológico e o social. Em todos estes três campos, ela se mantém fiel a um mesmo ponto de vista positivista: não se trata de explicar por que motivo se produzem os fenômenos, mas sim de descrever suas manifestações, de maneira sistemática e com a maior exatidão possível.

Atualmente, tornou-se amplamente difundida, na gerontologia internacional, com reforço e adesão da ONU, em oposição ao paradigma do ciclo de vida, a mudança para o envelhecimento como curso de vida que implica considerar a trajetória de vida das pessoas. Para Debert (1992, p. 37), uma perspectiva “[...] em que a velhice não seria pensada como um momento definido cronologicamente, mas como um processo gradual em que a dimensão histórica e social e a biografia individual devem ser consideradas como relevantes".

Segundo Carvalho (2013), o envelhecimento é um processo que integra fatores pessoais, econômicos, comportamentais, culturais, sociais e de gênero, os quais determinam o modo como se envelhece. Para Fonseca (2006 apud Carvalho, 2013, p. 5), “[...] esta noção ultrapassa a explicação do envelhecimento como idade, como algo estático e introduz explicações integradas e dinâmicas associadas ao percurso de vida dos sujeitos”.

Essas análises, apesar de considerarem o envelhecimento decorrente e determinado por inúmeros fatores, não conseguem superar a perspectiva teórica-sistêmica do todo como soma das partes, que são integradas, funcionais e interdependentes. Além disso, o indivíduo é analisado como autorregulado, consciente e capaz de deter os efeitos negativos do envelhecimento pelas mudanças de hábitos, comportamentos e modos de vida.

O curso, o percurso ou a trajetória de vida são bastante individualizados, singularizados. Mesmo que se levem em consideração outros 
determinantes, os macroestruturais são poucos abordados, especialmente nas pesquisas anglo-saxônicas, como já analisados por Gardner (2006) em uma revisão de literatura.

Na perspectiva do envelhecimento ativo ou saudável, que adota o paradigma do curso de vida, consideram-se os determinantes culturais e de gênero, mas muito restritos a hábitos como o tabagismo, o alcoolismo e as diferenças nesse consumo entre homens e mulheres, que se somam aos fatores comportamentais e pessoais. $\mathrm{O}$ ambiente físico e social limita-se a uma cidade adaptada aos idosos e ao apoio social. Os fatores econômicos são analisados em suas expressões fenomênicas, como renda, trabalho, proteção social, desagregados das classes sociais, suas frações e seus grupos, assim como o papel das políticas públicas com as ações de saúde e de serviços sociais.

Portanto, o reconhecimento da heterogeneidade do envelhecer é um consenso na gerontologia contemporânea. A OMS destaca: "[...] a perspectiva do curso de vida para o envelhecimento ativo reconhece que os mais velhos não constituem um grupo homogêneo e que a diversidade entre os indivíduos tende a aumentar com a idade" (WHO, 2005, p. 6).

Assim, o envelhecimento e a velhice passam a ser considerados fatos naturais e sociais, aprofundando a noção de processo biopsicossocial. Mas, como destaca Beauvoir (1970), somente uma descrição dos diferentes aspectos da velhice não é considerada suficiente para explicá-la, restringindo em descrevê-la, especialmente sua aparência, pois cada um desses aspectos interage com todos os outros e é por eles afetado, logo, é "[...] no movimento indefinido dessa circularidade que se deve apreendê-la" (Beauvoir, 1970, p. 16).

É nessa perspectiva, de superar as análises limitantes e positivistas, que a gerontologia crítica vem ganhando espaço. A perspectiva da totalidade utiliza o método histórico-dialético que é capaz de superar as aparências, a pseudoconcreticidade singularizante e chegar mediante um trabalho que utiliza categoriais simples às mais complexas, resgatando as mediações e as relações com a totalidade, desvendando as múltiplas 
determinações do fenômeno como um todo, síntese de múltiplas determinações, chegando a sua forma de ser, ontológica, não como apenas um produto da razão científica, mas também a reprodução do modo de ser da realidade.

Não se trata, como apontado por Siqueira, Botelho e Coelho (2002), de uma perspectiva de pesquisa na linha economicista, como as realizadas pelo marxismo vulgar de traços positivistas e estruturalistas, mas de uma perspectiva histórica-dialética que se situa nas condições de produção e reprodução social em sua totalidade dinâmica, processual e histórica, e que utiliza o método histórico-dialético no sentido de resgatar as relações entre singularidade/particularidade/totalidade. ${ }^{1}$

Nessa perspectiva de análise, considera-se o envelhecimento humano heterogêneo, mas não a ponto de ser considerado como uma experiência única, irrepetível, totalmente singular e subjetivista. A partir do método histórico-dialético, essa singularização é apenas o ponto de partida da análise, que representa uma totalidade parcial caótica, a qual esconde uma gama de relações e mediações determinantes que a liga à totalidade social, desvendado suas similitudes com outros casos. Dentre os determinantes que geram diferenças e semelhanças nos grupos, está a condição de inserção nas estruturas produtivas, que criou as diferenças entre as classes sociais, que são vividas de formas variadas conforme os condicionantes culturais diversos (gênero, raça-etnia e geracional) decorrentes das relações sociais engendradas pelo conjunto da vida social, sob determinado modo de produção e seus modelos de acumulação.

Assim, as situações de exploração, opressão e dominação que esses diferenciadores expressam, na sociedade capitalista, são elementos que produzem não apenas diferenças, mas também estão implicados em relações de desigualdades sociais diversas, reproduzidas ou ampliadas nesse tipo de sociedade.

Para maiores detalhes desse método nas análises do envelhecimento, ler Teixeira (2020; 2019; 2018). 
Nesse sentido, a homogeneidade é possível pelas condições de vida e de trabalho comuns. Embora a genética e a base biológica também sejam ontológicas, elas não explicam sozinhas nem as diferenças, nem as similitudes, embora tenham um peso na explicação das variações individuais quando submetidas às mesmas condições de existência de determinadas classes ou grupos. As inserções nas estruturas produtivas e culturais, ao mesmo tempo que diferenciam, entre as classes, por sexo, cor e etnicidade (formas de ser das classes sociais), também geram semelhanças. Assim, a homogeneização não é mais abstrata, mas marcada pela historicidade.

Os indivíduos, nessa ótica analítica, não são marionetes das estruturas que funcionam independentemente dos sujeitos. Mas também não representam o sujeito humanista/renascentista autônomo, livre, criativo e autoconsciente, fonte de todo o conhecimento e da ação moral e política, contra o qual o estruturalismo rivaliza. Como destacam Marx e Engels (1977), os homens fazem a história, mas em condições dadas que, mediante a práxis política, podem reconstruir, remodelar ou a transformar pela força do sujeito coletivo, como as classes sociais. Teixeira (2019, p. 181) defende que:

[...] considerar essas relações sociais estruturais não implica apenas permanências, recorrências e regularidades geradas pelas estruturas que agem sobre os sujeitos, que determinam suas práticas e formas de pensar, mas por serem históricas, construídas socialmente têm margem de resistência.

Nesta mesma perspectiva, sobre as resistências destaca Kergoat (2010, p.100), “[...] devemos estar atentos à maneira como os dominados reinterpretam e subvertem as categorias [...]. Porém, a subversão só pesa sobre as relações sociais se forem coletivas", ou seja, quando são mobilizadas pelas classes e suas frações e grupos em processos de lutas e resistências. As diferenciações internas da classe trabalhadora também geram diferentes condições de existência e experiências, com impacto no modo de envelhecer destas frações. 
2.1 As diferenças de classe: o envelhecimento da classe trabalhadora sobrante

Como destaca Motta (1999, p. 193), “[...] a vida social é estruturada em conjunto de relações que, em interface, ou articuladas dinamicamente, lhe dão sentido [...]. Os mais determinantes desses sistemas de relações são as classes sociais, os gêneros, as idades/gerações e as raças/etnias". Mas, alerta a autora, fundamentada nos estudos de Hirata e Kergoat: “[...] nenhum deles, analisados isoladamente, dá conta da complexidade da realidade, pois as mesmas são co-extensivas [...]" (Motta, 1999, p. 193), ou seja, determinam-se entre si, se articulam umas às outras, entretanto, é possível identificar os nós de interseção desses determinantes.

A condição de classe é um dos diferenciadores das experiências do envelhecimento. Um abismo separa o envelhecimento da classe dominante - que sempre foi longeva - da classe trabalhadora.

As classes também não podem ser analisadas como unas e indiferenciadas. Elas compõem diferenciações formando frações e grupos no seu interior. Assim como Poulantzas (1985) analisou a relação do Estado com as diversas frações da classe dominante, é possível ampliar essas análises e incluir as frações da classe trabalhadora, embora todos se incluam, por mais diversos que sejam, na classe-que-vive-do-trabalho (Antunes, 2018).

Analisar os determinantes macroestruturais do envelhecimento implica considerar a sociedade classista sob o capitalismo e seus diversos modelos de acumulação e regulação social, e suas leis de funcionamento. Destaca-se a lei da acumulação, em que o capital, em virtude da concorrência e da busca pelos superlucros, tem que se revolucionar constantemente, buscando aumentar a produtividade, diminuir o tempo médio de produção da mercadoria para ganhar mercados, e é impelido a investir gradativamente em capital constante (maquinaria e tecnologia) e diminuir o capital variável (força de trabalho), reduzindo a massa empregável, processos que geram a centralização e a concentração, em poucas mãos, das riquezas produzidas. 
A acumulação implica mobilização e ampliação dos trabalhadores, o que não significa sua empregabilidade, pois, essa sociedade “[...] sempre produz, e na proporção da sua energia e de sua extensão, uma população trabalhadora supérflua relativamente, isto é, que ultrapassa as necessidades médias da expansão do capital, tornando-se, desse modo, excedente" (Marx, 1982, p. 731).

A essa população excedente Marx (1982) cunhou de superpopulação relativa, existente sob variadas formas, e que todo trabalhador faz parte dela quando está desempregado. Segundo o estudioso, ao analisar a realidade do século XIX, tal superpopulação assumia três formas principais: flutuante, latente e estagnada.

$\mathrm{Na}$ forma flutuante, os trabalhadores experimentam períodos de expansão e de crise do sistema capitalista, por isso "[...] são ora repelidos, ora atraídos em quantidade maior, de modo que, no seu conjunto, aumenta o número dos empregados, embora em proporção que decresce com o aumento da escala da produção" (Marx, 1982, p. 743-744). Quando repelidos, em períodos de crises e recessões, entram no desemprego e passam a buscar novo emprego.

A segunda forma, a latente, atinge parte dos trabalhadores rurais que, diante dos excedentes de trabalhadores no campo, e em condições precárias de existência da economia familiar rural, são mobilizados pela ideia de ascensão social nas cidades e melhores condições de vida e podem, a qualquer momento, engrossar as fileiras dos proletariados urbanos ou de suas franjas desempregadas e em busca de trabalho.

A terceira forma, a estagnada, é composta pelos trabalhadores informais que, segundo Marx (1982, p. 746), “[...] se amplia à medida que o incremento e a energia da acumulação aumentam o número dos trabalhadores supérfluos [...]", os quais, para sobreviverem a longos períodos de desemprego, passam a desempenhar ocupações informais.

Há, ainda, uma última parcela da superpopulação relativa que compõe o pauperismo e que constitui o que $\operatorname{Marx}(1982$, p. 747) chama de “[...] asilo dos inválidos do exército ativo dos trabalhadores e o peso morto do 
exército industrial de reserva". Os inválidos, degradados, desmoralizados, incapazes de trabalhar por doenças, velhice, deficiências e filhos e órfãos de indigentes, que compõem o pauperismo absoluto.

Assim, têm-se três frações bem nítidas na classe trabalhadora: a dos inseridos no mercado formal e com proteção social trabalhista e direitos sociais; a da superpopulação relativa, que é a população sobrante, excedente e sem proteção das leis trabalhistas; e a massa de pobres, que não trabalham por incapacidades, desmoralização, estigmatização, na qual estão incluídos os indigentes, seus filhos e órfãos com baixa capacidade de superarem a condição dos pais, ou ciclo da pobreza, quando adultos ou velhos.

Com certeza, as frações da classe trabalhadora que compuseram e compõem a superpopulação relativa terão a velhice marcada por maiores vulnerabilidades e desigualdades, que incidem nas estruturas biológica e psicológica. Essas desigualdades são cumulativas quando são mulheres, negras, imigrantes e velhas.

\subsection{Envelhecimento da classe trabalhadora em contexto de economias dependentes e de superexploração}

A longevidade entre os trabalhadores e suas diferentes frações de classe é diferenciada, bem como a sobrevida após os 60 anos. Essa diferenciação, mascarada pelas médias estatísticas da demografia, é a expressão mais crua das desigualdades sociais e que se revela em indicadores variados de expectativa de vida entre continentes, países (e, dentro de um mesmo país), pode variar entre regiões, estados e municípios, sempre acompanhado a divisão internacional e local do trabalho.

Nos países latino-americanos, especialmente o Brasil, devido à inserção subordinada na divisão internacional do trabalho, e para contra-arrestar as relações desiguais no comércio internacional, a classe burguesa dependente sempre utilizou um artifício: a superexploração da força de trabalho. 
Essa superexploração, segundo Marini (2005), pode ser observada tanto na apropriação do trabalho excedente produzido pela força de trabalho, quanto na remuneração abaixo do valor necessário à reprodução dessa força de trabalho. Essa superexploração é marcada pela utilização de meios, como a intensificação da jornada de trabalho ou sua extensividade, ampliando o tempo de trabalho, ou seja, incide tanto no uso da mais-valia relativa como na absoluta, com baixos salários, que “[...] sequer garante[m] o valor dos bens de reposição da força de trabalho no que diz respeito ao dispêndio físico-psíquico, como também no dispêndio do tempo de vida laboral e da vida total" (Diligenti; Araujo, 2019, p. 69).

Essas economias dependentes se especializaram em abastecer as economias centrais com produtos primários (agrário-minerais), aqueles que servem para garantir matérias-primas para as indústrias e para a cesta básica dos trabalhadores desses países. Como importam produtos industrializados, tecnologias e outros produtos de luxo, a balança comercial fica desequilibrada e, nessas negociações, o valor produzido nesses países é transferido para as economias centrais, compensado pelo uso da superexploração da força de trabalho local.

Mesmo com o processo de industrialização tardia, como é o caso brasileiro, não houve rompimento com essas relações desiguais, pois se utilizavam tecnologias obsoletas daqueles países. Além disso, a industrialização de substituição da importação nunca se dirigiu para o consumo de massa que obrigaria a ampliação dos salários para manter o consumo, especializando-se em produtos suntuários, para os quais já havia mercado.

A superexploração incide decisivamente na trajetória de vida dos trabalhadores, assim como a exclusão desse mercado de trabalho formal restrito, ampliando, em larga escala, a superpopulação relativa. Exatamente porque é muito extensiva, essa superpopulação relativa viabiliza a superexploração, sendo característicos dessas economias a alta rotatividade da força de trabalho e os baixos salários. Outra situação gritante é a do exército de inativos que compõem o pauperismo absoluto. 
Portanto, o esgotamento prematuro é uma perspectiva real para o trabalhador formal, "...] porque lhe é obrigado um dispêndio de força de trabalho superior ao que deveria proporcionar normalmente [...] é retirada inclusive a possibilidade de consumo do estritamente indispensável para conservar sua força de trabalho em estado normal [...]" (Marini, 2005, p. 156-157), esse esgotamento também atinge os que vivem na informalidade, pois, além de longas jornadas, não lhes são assegurados quaisquer direitos trabalhistas.

Mesmo com esse quadro, a população nos países dependentes vem conseguindo envelhecer, em proporção rápida, em relação aos países centrais, vivendo uma etapa de transição demográfica e epidemiológica. Como destaca Capucha (2014), esse fenômeno mundial não se deve apenas aos avanços da medicina e das tecnologias de saúde, mas, principalmente, ao Estado social e ao sistema de proteção social, como as políticas públicas, que permitiram que esses avanços da medicina fossem socializados e chegassem à população - campanhas de saúde, vacinação, combate a endemias, distribuição gratuita de remédios, acesso ao sistema público de saúde de forma gratuita, que se soma ao saneamento básico, à água tratada e canalizada, à coleta de lixo, à habitação digna, às políticas de transferência de renda (pensões, aposentadorias e benefícios assistenciais), à política de educação, dentre outras.

Na periferia do sistema, o Estado social não se materializou como um vasto sistema de proteção social inclusivo, mas, mesmo assim, conseguiu criar um conjunto de políticas públicas que, mesmo de forma incipiente, com precários níveis de investimentos e qualidade dos serviços, foram essenciais para que se vivesse o fenômeno do envelhecimento demográfico, especialmente para que a classe trabalhadora pudesse envelhecer, embora marcada por desigualdades ainda não superadas e até agudizadas na atual conjuntura.

De acordo com Sampaio Júnior (2017 apud Diligente; Araujo, 2019, p. 68), “[...] o Brasil vive um processo de reversão neocolonial [...]”, como pode se visualizar pela economia de commodities, atualizada no mercado mundial, além de outras expressões como: 
[...] a reprimarização da economia; a desindustrialização, a privação da soberania sobre os recursos naturais, a predominância do capital rentista e uma série de retrocessos em diferentes direitos sociais e trabalhistas, com destaque para as reformas trabalhista e da previdência (Diligente; Araujo, 2019, p. 68).

Na contemporaneidade, em tempos de hegemonia do capital financeiro, exacerbam-se as condições de exploração da força de trabalho, sendo a superexploração um recurso que vem se generalizando também em países centrais, como estratégia de redução de custos e retomada das altas taxas de lucros em períodos de crises. Como destaca Antunes (2018, p. 62, grifos do autor), “[...] a superexploração do trabalho, então, deixou de ser um discreto charme da burguesia dependente e subordinada e adentrou o coração do welfare state".

Esse processo vem se tornando possível devido à legalização e à ampla utilização da precarização das condições de trabalho, dos contratos, dos salários, das jornadas de trabalho e de suas modalidades diversas - sob a denominação de flexibilidade, acompanhada da alteração do padrão de proteção social, como nas leis trabalhistas -, e dos direitos sociais. Isso porque, para dar legitimidade e condições de expansão desse modelo de acumulação flexível, foi necessária atualização na superestrutura jurídica, política e ideológica.

A resultante do processo de crise e das saídas flexíveis, financeirizadas e neoliberais tem sido o desemprego estrutural, permanente, de longa duração, com a ampliação sem precedentes da superpopulação relativa, especialmente da estagnada, com o crescimento da informalidade, a única ocupação que vem crescendo nos países centrais e periféricos, além do crescimento dos que se encontram em estado de pobreza absoluta.

No capitalismo atual, a superpopulação relativa adquire novas dimensões e configurações. Os sobrantes se avolumaram nos últimos anos, não apenas os tradicionais, com baixa escolaridade e qualificação, mas também os qualificados e com elevado grau de escolaridade. A rotatividade se ampliou pelas elevadas metas a serem atingidas em 
indústrias, empresas e setores de serviços, e a disponibilidade de mão de obra sobrante. Além disso, a precarização se tornou oficial, legítima.

Antunes (2018, p. 156), numa fenomenologia dos novos modos de ser da precarização, destaca a: "[...] ampliação de trabalhos submetidos a sucessivos contratos temporários, sem estabilidade, sem registro em carteira, [...] quer em atividades mais instáveis, quer nas temporárias, quando não na situação de desemprego". Nesse processo, a terceirização tem sido um dos elementos mais decisivos para a legitimação da precarização.

Na periferia do sistema, que tem se reprimarizado com a economia de commodities, a situação se agrava ainda mais. Citando exemplos da agroindústria (da canavieira, da avícola, dentre outras), Antunes (2018, p. 128) ressalta que “[...] os adoecimentos, as mutilações e o envelhecimento precoce passam a fazer parte do cotidiano dos trabalhadores da agroindústria”. De forma geral, essas novas condições de trabalho na indústria, nos serviços, na agroindústria e em outros setores têm contribuído para ampliar a deterioração das condições de saúde, ampliam os riscos de acidentes, a exaustão, o desgaste físico e psíquico acelerado devido aos assédios e às pressões por aumento da produtividade.

Em tempos de flexibilização e de hegemonia do capital financeiro, “[...] é a lógica do curto prazo, que incentiva a 'permanente inovação' no campo da tecnologia, de novos produtos financeiros e da força de trabalho, tornando obsoletos e descartáveis os homens e mulheres que trabalham [...]" (Antunes, 2018, p. 153-154), ou grande parte deles.

Essa realidade mundial, segundo Silveira Júnior (2019), tem no Brasil uma expressão singular, cujas mediações desvendam suas relações mais gerais com o modo e as contradições na produção de riqueza na contemporaneidade, que, no país, segundo o autor, tendem a conformar uma paisagem aterradora, com a ampliação do desemprego, da informalidade e a usurpação do fundo público, especialmente da parcela destinada às políticas sociais e à reprodução da força de trabalho e da sua família, o que torna o sistema de proteção social público-alvo de desmonte e de investidas do capital, para oferecer serviços antes amplamente 
desmercadorizados, sendo necessário mercantilizá-los e ofertá-los pelo mercado privado; e também a difusão da lógica de redução do gasto público e da política de austeridade para garantir o pagamento dos juros da dívida pública, que tem no capital financeiro seu principal investidor.

Segundo Silveira Júnior (2019), é nesses termos de rebaixamento do valor da força de trabalho, flexibilidade para explorar ainda mais, de forma legalizada e legítima, e da apropriação de parcelas crescentes do orçamento público relativo às políticas sociais que devem ser compreendidas as atuais contrarreformas brasileiras, como a reforma trabalhista (Lei n. 13.467/2017), a Lei da Terceirização (Lei n. 13.429/2017) e a Reforma da Previdência Social (PEC n. 06/2019).

Segundo o Silveira Júnior (2019, p. 179):

[...] essas iniciativas colaboram para estender o tempo de trabalho sem acréscimo proporcional na forma salário; intensificar o desgaste psicofísico dos/as trabalhadores/as, com desmantelamento dos controles que limitavam (minimamente) a jornada e as circunstâncias laborais extenuantes; a contração do tempo livre para a reposição das energias corpóreas e psíquicas do trabalho vivo; o aumento dos custos da reprodução da força de trabalho, que recai sob os ombros dos/as próprios/as trabalhadores/as; prolongamento do tempo excedente, através dos acréscimos na extensão absoluta das jornadas, paralelo à corrosão da retribuição do tempo necessário expressa em salário [...].

Essa realidade é prova inconteste de que os indivíduos, a depender da sua inserção de classe e das frações e dos grupos de classe, têm pouca ingerência nas suas condições de vida e trabalho, bem como no estilo de vida, dominado pelo tempo do capital, trabalho assalariado ou em busca da sobrevivência, influenciando, inclusive, na incidência de doenças e no envelhecimento físico e psíquico precoce. Todavia, como destacam Marx e Engels (1977, p.07), "a história de toda as sociedades que existiram até nossos dias tem sido a história das lutas de classes", ou seja, de ofensivas e de resistências, de lutas que promovem mudanças ou permanências. 
A criação dos sistemas de proteção social públicos, fruto do pacto de classe, que dependeu do processo de organização da classe trabalhadora, hoje diante da ofensiva do capital está em vias de dissolução ou de alterações substanciais que os desconfiguram e comprometem o futuro das atuais gerações dos adultos jovens (a massa que hoje se submete para sobreviver aos contratos "zerados", "uberizados", "pejotizados", "intermitentes", "flexíveis" e aos trabalhos informais) e dos/as atuais idosos/as afetados com as contrarreformas, especialmente, na previdência social, e com a ampliação da pobreza.

\section{Considerações finais}

Contraditoriamente, as formas de "reprivatização da velhice" (Debert, 1999) se expandem nessa conjuntura, que, em nome de uma suposta valorização e do reforço da solidariedade intergeracional, retomam para os indivíduos e as famílias as responsabilidades pelas condições em que envelhecem e difundem que é possível deter os efeitos mais deletérios do envelhecimento por mudanças de hábitos, comportamentos e estilos de vida. Essa falsa crença de que, agora, na velhice, é possível determinar as formas de sua existência enfrenta limites, dados os baixos valores da aposentadoria, o retorno ao trabalho na condição informal ou precarizado, os cortes de benefícios, a limitação no acesso aos serviços públicos, dentre outros.

As receitas gerontológicas de "faça da sua velhice uma terceira idade" mascaram outras formas de envelhecer, como a dependente de cuidados, doentia, marcadas pela pobreza e por inúmeras vulnerabilidades, e tratam esses problemas como individuais, resultantes da incapacidade das pessoas de gerirem os riscos sociais e naturais da existência, e não como uma questão de políticas públicas.

As políticas públicas contemporâneas são redesenhadas por um modelo também flexível, plural, misto de proteção pública e privada, em que o primeiro, restrito aos mais pobres, ocorre em parceria com ONGs, família, 
vizinhança e outros modos informais. Já se naturalizou a noção de que não se fazem políticas públicas sem as parcerias, sendo sinônimas de modernização, de democratização, ao envolver uma variedade de atores sociais e instituições de origens diferentes para formar redes de proteção social.

A centralidade na família promovida pelas políticas sociais é um reforço do familismo, pois potencializa os recursos familiares no cuidado e na assistência aos seus membros, incluindo os idosos, ao invés de serem fontes de apoio, de assistência e cuidados para amenizar e diminuir os custos relativos a essas fontes.

Em contexto de austeridade fiscal neoliberal, recairão sobre os próprios indivíduos e suas famílias as responsabilidades pela proteção social diante da precarização (por falta de investimentos) das políticas sociais, enquanto o fundo público é canalizado para as amplas necessidades de superlucros do capital financeiro.

Mesmo com a precarização das condições de existência da classe trabalhadora, com a generalização da superexploração, com o crescimento avassalador da superpopulação relativa e dos em situação de pobreza, destacam-se, ainda de forma predominante, estudos que analisam o envelhecimento na perspectiva restrita biomédica, seja a homogeneizante, seja a que o destaca como um processo heterogêneo. Ambas sem nenhuma análise da realidade social em que as pessoas vivem e envelhecem. Não sendo rara a defesa das atuais contrarreformas nas políticas sociais, em nome do equilíbrio dos gastos com o envelhecimento. Mas as oposições existem e precisam se consolidar como coletivas também no modo de produzir conhecimento sobre o envelhecimento.

\section{Referências}

ANTUNES, R. O privilégio da servidão: o novo proletariado de serviços na era digital. São Paulo: Boitempo, 2018.

BEAUVOIR, S. de. A velhice. Tradução: Maria Helena Franco Monteiro. Rio de Janeiro: Nova Fronteira, 1970. 
CAPUCHA, L. Envelhecimento e políticas sociais em tempos de crise. Sociologia, Problemas e Práticas, Lisboa, n. 74, p. 113-131, fev. 2014.

CARVALHO, M. I. de. Um percurso heurístico pelo envelhecimento. In: CARVALHO, M. I. de. Serviço social no envelhecimento. Lisboa: Pactor, 2013.

DEBERT, G. G. Família, classe social e etnicidade: um balanço da bibliografia sobre a experiência de envelhecimento. BIB, Rio de Janeiro, n. 33, p. 33-49, jan./jun. 1992.

DEBERT, G. G. A reinvenção da velhice: socialização e processos de reprivatização do envelhecimento. São Paulo: Edusp; Fapesp, 1999.

DILIGENTE, M. P.; ARAUJO, R. S. Nova previdência: o austericídio neoliberal sob a ótica da teoria marxista da dependência. Textos \& Contextos, Porto Alegre, v. 18, n. 1, p. 67-77, jan./jun. 2019.

GARDNER, P. J. Envelhecimento saudável: uma revisão de literatura. Movimento, Porto Alegre, v. 12, n. 2, p. 69-92, maio/ago. 2006.

KERGOAT, D. Dinâmica e consubstancialidade das relações sociais. Novos Estudos, n. 86, p. 93-103, mar. 2010.

MARINI, R. M. Dialética da dependência. In: MARINI, R. M. Ruy Mauro Marini: vida e obra. São Paulo: Expressão Popular, 2005.

MARX, K. O capital: crítica de economia política. 8. ed. São Paulo: Difel, 1982. v. 2, Livro 1.

MARX, K.; ENGELS, F. A ideologia alemã (Feuerbach). São Paulo: Gripalbo, 1977.

MOTTA, A. B. da. As dimensões de gênero e classe social na análise do envelhecimento. Cadernos Pagu, Campinas, n. 13, p. 191-221, 1999.

POULANTZAS, N. O Estado, o poder e o socialismo. 2. ed. Rio de Janeiro: Edições Graal, 1985.

SCHNEIDER, R. H.; IRIGARY, T. O. O envelhecimento na atualidade: aspectos cronológicos, biológicos, psicológicos e sociais. Estudos de Psicologia, Campinas, v. 25, n. 4, p. 585-593, out./dez. 2008.

SILVEIRA JÚNIOR, A. As condições das classes trabalhadoras nas circunstâncias da crise e restauração no Brasil atual. Textos \& Contextos, Porto alegre, v. 18, n. 1, p. 174-188, jan./jun. 2019.

SIQUEIRA, R. L. de; BOTELHO, M. I. V.; COELHO, F. M. G. A velhice: algumas considerações teóricas e conceituais. Ciência \& Saúde Coletiva, v. 7, n. 4, p. 899-906, jun./dez. 2002.

TEIXEIRA, S. M. O envelhecimento e as reformas no sistema de seguridade social no Brasil contemporâneo. Textos \& Contextos, Porto Alegre, v. 17, n. 1, p. 126-137, jan./jul. 2018. 
TEIXEIRA, S. M. Envelhecimento e a proposta de "reforma" da previdência social: implicações para os velhos e as velhas trabalhadoras/es. In: TEIXEIRA, S. M. Envelhecimento e políticas sociais em contexto de crises e contrarreformas. Curitiba: CRV, 2019.

TEIXEIRA, S. M. Envelhecimento, família e políticas públicas: em cena a organização social do cuidado. Serviço Social \& Sociedade, São Paulo: Cortez, n. 137, p. 135-154, jan./ abr. 2020.

WHO. Envelhecimento ativo: uma política de saúde. Tradução: Suzana Gontijo. Brasília: Organização Pan-Americana da Saúde, 2005.

\section{Sobre a autora}

Solange Maria Teixeira - Doutora em Políticas Públicas com pós-doutorado em Serviço Social. Docente do Programa de Pós-Graduação em Políticas Públicas e do curso de Serviço Social. Bolsista de produtividade do CNPq, Membro do Comitê de Assessoramento da área de Psicologia e Serviço Social no CNPq e Pesquisadora Visitante da UNESP, campus de Franca.

E-mail: solangemteixeira@hotmail.com 